\title{
Saberes da experiência para a formação do cotidiano de homens e mulheres da Comunidade do Rosado/RN ${ }^{1,2}$
}

\section{Knowledge of the experience for the daily formation of men and women of the Community of Rosado/RN}

\author{
STENIO DE BRITO FERNANDES \\ Mestre em Educação pela Universidade do Estado do Rio Grande do Norte-UERN \\ Professor IV de Geografia Perm. Nível (SEEC/RN) \\ steniondre@hotmail.com
}

ANA LÚCIA OLIVEIRA AGUIAR

Doutora em Sociologia pela Universidade Federal da Paraíba-UFPB; Pós-doutora pelo Programa de Pós-Graduação em Educação da Universidade Federal do Ceará-UFC.

Professora Adjunta IV.

oliveiraaguiarpetro@gmail.com

\begin{abstract}
RESUMO
A pesquisa objetiva compreender como os saberes da experiência de homens e mulheres contribuem para a formação do cotidiano na Comunidade do Rosado/RN. Optamos pelo uso da abordagem qualitativa. Utilizamos como método de investigação a pesquisa (auto)biográfica a partir das narrativas de quatro moradores centrais da comunidade que participaram da pesquisa. No caminhar da pesquisa, apontamos como resultados que os saberes da experiência de homens e mulheres estão sendo compartilhados entre seus moradores, desde as gerações passadas, e preservados pelas novas gerações. Saberes como pescar, plantar, ensinar, cantar, bordar, rezar, costurar, entre outros, são praticados e repassados pelos adultos e jovens na contemporaneidade. Esse processo contribui para a formação do cotidiano na comunidade, nos seus espaços de possibilidades, nas tradições, nos costumes e nos saberes da experiência para a formação do ensinar, aprender, conviver e ser, a partir do pertencimento do seu lugar, na construção da memória individual e coletiva.
\end{abstract}

Palavras-chave: Saberes da experiência. Narrativas (auto)biográficas. Memória. Formação.

\begin{abstract}
The objective research understand, how the knowledge of the experience of men and women contribute to the formation of daily in the community of Rosado/RN. We chose to use the qualitative approach. We used the method (auto) biographies research from the narratives of four central residents of the research. In the walk of research in, we point out the results that the knowledge of the experience of men and women have been shared among its residents, from the past generations, and preserved by the new generations. These knowledges such as: fishing, planting, teaching, singing, embroidering, prayer, sewing, among others, are practiced and passed on by adults and young people today. This process contributes to the formation of daily life in the community, in its spaces of possibilities, in the traditions, customs and knowledge of the experience for the formation of teaching, learning, coexisting and being, from the belonging of its place, in the construction of individual and collective memory.
\end{abstract}

Keywords: Knowledge of the experience. (auto)biographies narratives. Memory. Formation.

\footnotetext{
${ }^{1}$ Artigo submetido para avaliação em 20/06/2019 e aprovado em 24/03/2020.

${ }^{2}$ Este trabalho apresenta resultados da pesquisa da dissertação de mestrado, intitulada Contar a vida, construir a formação: narrativas de empoderamento dos povos do mar da Comunidade do Rosado/RN, defendida em 2018 pelo Programa de Pós-Graduação em Educação (POSEDUC) da Universidade do Estado do Rio Grande do Norte (UERN), e relaciona-se à linha de pesquisa: Práticas educativas, Cultura, Diversidade e Inclusão.
} 
Rev. Interd. em Cult. e Soc. (RICS), São Luís, v. 6, n. 1, p. 214- 234, jan./jun. 2020

ISSN eletrônico: 2447-6498

\section{INTRODUÇÃO}

A construção da pesquisa baseia-se em saberes da experiência, que deve ser compreendida em uma perspectiva formativa através das narrativas (auto)biográficas da realidade de homens e mulheres da Comunidade do Rosado, distrito do município de Porto do Mangue, localizada geograficamente na faixa litorânea da região Nordeste do Brasil, especificamente na costa setentrional do estado do Rio Grande do Norte. O local possui aproximadamente 720 habitantes $^{3}$. É um lugar de paisagens que encantam os olhos de quem o visita. As falésias, as dunas e a vegetação da Caatinga avançam do interior até o litoral e, podemos dizer, o sertão encontra o mar.

Definimos essa comunidade como lócus de pesquisa devido à nossa convivência pessoal e profissional há mais de treze anos com os seus moradores. É um lugar fértil de saberes da experiência formadora para o campo da pesquisa (auto)biográfica. A memória aflora nas lembranças e recordações vividas ao longo da história dos sujeitos, na relação de educar e formar para a sensibilidade dos saberes da experiência.

Na Comunidade do Rosado/RN, os moradores desconhecem a origem do nome Rosado. Para alguns pesquisadores que estiveram no local, ela está relacionada à combinação de cores entre os sedimentos esbranquiçados das dunas com os terrenos avermelhados e alaranjados dos latossolos ${ }^{4}$ e barreiras ${ }^{5}$, que resultam na coloração rosada. Porto do Mangue faz parte da chamada Zona Homogênea Mossoroense, delimitada pelo Instituto de Defesa do Meio Ambiente do Rio Grande do Norte (IDEMA/RN).

A essa comunidade pertence uma história de luta e resistência pelo direito à dignidade, à moradia e à educação. Desde 1991, constitui um histórico de lutas e resistências pelo direito à terra. Essa luta culminou na morte de um morador em defesa da terra de 72 famílias. Construída por meio de forças oriundas do pertencimento do lugar e da participação da população na construção e desenvolvimento dos espaços em que habita. Na Associação Sebastião Andrade da Comunidade, os membros fazem reuniões para refletir sobre os problemas e as condições sociais do seu cotidiano. As conquistas, ao longo do tempo, são

\footnotetext{
${ }^{3}$ Essa informação foi fornecida pela Secretaria de Ação Social de Porto do Mangue/RN, com base nos dados censitários de 2009.

${ }^{4}$ Solos constituídos predominantemente por material mineral, em geral profundos, velhos, bem drenados, baixo teor de fragmentos de rocha, baixo teor de materiais facilmente intemperizáveis, homogêneo, estrutura granular, sempre ácidos, nunca hidromórficos.

${ }^{5}$ Cobertura de origem Sedimentar Continental; Tabuleiros com altitude média de 40m acima do nível do mar. Sedimentos de Granulometria Variada formados por areia, silte e argila com concreções ferruginosas.
} 
Rev. Interd. em Cult. e Soc. (RICS), São Luís, v. 6, n. 1, p. 214- 234, jan./jun. 2020 ISSN eletrônico: 2447-6498

frutos da força e união das associações, sindicatos e movimentos sociais, por meio de reivindicação por cidadania.

A comunidade é um espaço de diferentes saberes, onde os sujeitos se confirmam, modificam e ampliam suas memórias, reconstroem o passado e planejam o futuro, na convivência com o outro. Adentrar no universo das histórias de vida e de formação dos sujeitos da Comunidade do Rosado/RN é comungar um mundo de saberes socialmente referenciados que ensinam. O universo da comunidade é construído na relação com o outro, por meio da convivência no cotidiano de homens e mulheres que exercem diversas atividades econômicas e desenvolvem diferentes funções sociais, tais como: pescadores, marisqueiras, artesãos, poetas, cordelistas, agricultores, líderes comunitários, sindicalistas, professores, entre outros.

A visita à Comunidade do Rosado/RN permitiu uma viagem no tempo através da memória guardada e que, agora, será repassada em narrativas de quatro moradores centrais da comunidade que participaram da pesquisa.

A construção desta pesquisa contribui para visibilidade aos saberes da experiência de moradores da Comunidade do Rosado/RN no seu espaço de possibilidades, de resistências e conquistas. Apontamos as narrativas (auto)biográficas de histórias de vida como um processo de formação de fazeres e saberes da experiência de homens e mulheres do mar, que defendem seu lugar de pertença na construção da memória viva em coletividade.

Para compreender os estudos na área do conhecimento sobre saberes da experiência, narrativas e histórias de vida de homens e mulheres do mar, fizemos um mapeamento do estado do conhecimento nas bibliotecas digitais da Coordenação de Aperfeiçoamento de Pessoal do Nível Superior (CAPES), da Universidade Federal do Rio Grande do Norte (UFRN) e da Universidade do Estado do Rio Grande do Norte (UERN). Centralizamos a busca nos títulos e nas palavras-chave de quarenta e três trabalhos. Destes, oito são teses e trinta e cinco são dissertações relacionadas com o tema da pesquisa. Após a leitura e interpretação dos seus resumos, foi possível considerar ou desconsiderar trabalhos que sinalizavam para outras dimensões ou pouco mencionavam sobre o tema de interesse. Em decorrência disso, foram destacados apenas cinco trabalhos, assim distribuídos: duas teses e três dissertações, defendidas entre os anos de 2005 e 2015. Esse recorte temporal está ligado ao fato de todos os trabalhos selecionados para esta pesquisa estabelecerem uma relação com o tema da proposta aqui apresentada, pois consideram o ano de 2005 adiante como período de investigação. 
Rev. Interd. em Cult. e Soc. (RICS), São Luís, v. 6, n. 1, p. 214- 234, jan./jun. 2020

Segue a descrição dos trabalhos que enfocam conceitos como saberes da experiência, narrativas e histórias de vida: (1) Ana Cláudia Mafra da Fonseca, Histórias de Pescador: as culturas populares nas redes das narrativas (Papary - Nísia Floresta - RN), tese de Doutorado em Letras, 2005; (2) Andreia Duarte Alves, Histórias de pescadores: memórias de vidas submersas, dissertação de Mestrado em Psicologia, 2007; (3) José Josberto Montenegro Sousa, Culturas tradicionais no Ceará: nas dobras de narrativas em contendas sertanejas, tese de Doutorado em História, 2009; (4) Mariene Francine Lima, Mares e Pescadores: narrativas e conversas em Itapoá, dissertação de Mestrado em Educação, 2011; (5) Roseli da Silva Cardoso, Os saberes da gente do mar: o imaginário e as experiências de vida dos pescadores da Vila do Treme, Bragança (PA), dissertação de Mestrado em Linguagens e Saberes na Amazônia, 2015.

Nos trabalhos selecionados, constatamos que todos imprimiram uma relevante contribuição para a pesquisa sobre saberes da experiência e narrativas de histórias de vida de homens e mulheres do mar. As pesquisas foram pautadas pela procura para dar sentido às ações e narrativas de pescadores, artesãs, cordelistas, agricultores entre outras profissões, sobretudo no que se refere às dimensões de tempo e de espaço. Essas orientam o viver entre a terra e o mar, sob o enfoque da memória e do imaginário em relação à configuração local.

A trajetória percorrida neste estudo sinaliza para uma pesquisa qualitativa em educação no campo do conhecimento das Ciências Humanas. Utilizamos a pesquisa qualitativa com base em autores como Bogdan e Biklen (1994). De acordo com os autores, a investigação qualitativa em educação assume muitas formas, por conseguinte, é conduzida em múltiplos contextos. A pesquisa qualitativa, segundo os autores, é formulada com o objetivo de investigar os fenômenos em toda a sua complexidade e em contexto natural. Nesse ambiente de construção da pesquisa, é privilegiada, essencialmente, a compreensão dos comportamentos a partir da perspectiva dos sujeitos da investigação.

A compreensão da (auto)biografia como um método no processo de transformações do sujeito surge em um contexto intelectual dinamizado pela invenção de si próprio e da valorização da subjetividade e das experiências privadas. O caminho proposto pela Metodologia das Histórias de Vida $^{6}$ em Formação é a narrativa, proposta por Josso

\footnotetext{
${ }^{6} \mathrm{O}$ método das histórias de vida indica caminhos da autoformação, segundo Pineau (2010, p. 167), "considera as histórias de vida como um método de investigação-ação, que procura estimular a autoformação, na medida em que o esforço pessoal de explicitação de uma dada trajetória de vida obriga a uma grande implicação e contribui para uma tomada de consciência individual e coletiva. A biografia é, simultaneamente, um meio de investigação e um instrumento pedagógico: é essa dupla função que justifica a sua utilização no domínio das ciências da educação e da formação".
} 
Rev. Interd. em Cult. e Soc. (RICS), São Luís, v. 6, n. 1, p. 214- 234, jan./jun. 2020

ISSN eletrônico: 2447-6498

(2010), pois permite explicitar a singularidade e, com ela, vislumbrar o universal, perceber o caráter processual da formação e da vida, articulando espaços, tempos e diferentes dimensões de nós mesmos em busca de uma sabedoria de vida. Essa abordagem histórica, teórica e metodológica, para Souza (2006), é entendida como pesquisa narrativa, ou Histórias de Vida em Formação. Com os estudos centralizados nas práticas de formação, o sujeito em construção passa a ser protagonista da sua própria história de vida, no seu cotidiano na relação de si e com o outro. Segundo Souza (2006), nas áreas das ciências sociais, as pesquisas com história de vida têm utilizado terminologias diferentes e, embora considerem os aspectos metodológicos e teóricos que as distinguem como constituintes da abordagem biográfica que utiliza fontes orais, delimitam-se na perspectiva da História Oral.

Para este estudo ${ }^{7}$, as narrativas de moradores do local investigado têm sua força no momento em que permitem a esses sujeitos uma (re)significação da prática na convivência diária, consigo e com o outro. Tal exercício fortalece e remete a uma perspectiva positiva e retificadora do pensamento crítico e reflexivo do ser em formação. O método (auto)biográfico apresenta-se para esta pesquisa como alternativa para a mediação entre as ações e a estrutura, entre a história individual e a história social. Por essa razão, requer dos sujeitos o resgate de suas memórias. A abordagem biográfica é classificada, conforme Souza (2006), como método ou técnica, ou os dois simultaneamente. Também pode ser denominada de história de vida, podendo apresentar diferentes variações diante do contexto e campo de utilização. Para Josso (2010), a abordagem biográfica tanto é método, porque logrou no seu processo histórico vasta fundamentação teórica, quanto técnica, porque também passou por conflitos, consensos e implicações teórico-metodológicas sobre a sua utilização.

Trazemos como pergunta problematizadora: como os saberes da experiência de homens e mulheres contribuem para a formação do cotidiano na Comunidade do Rosado/RN? Para refletir sobre esta questão, tivemos como objetivo geral compreender como os saberes da experiência de homens e mulheres contribuem para a formação do cotidiano na Comunidade do Rosado/RN, identificando elementos teórico-metodológicos dessa formação com base nas narrativas (auto)biográficas.

\footnotetext{
${ }^{7}$ Este estudo deixará contribuições escritas para a comunidade investigada e para mim, que, a partir da própria pertença ao lugar, há alguns anos, pude conviver com o campo da pesquisa. A contribuição das narrativas das histórias de vida, dos saberes da experiência de homens e mulheres do mar da Comunidade do Rosado/RN, em suas páginas, ficará no registro desses saberes, tanto para a Comunidade do Rosado/RN como para a comunidade acadêmica. O estudo na Comunidade do Rosado/RN enfocará historicamente os saberes da experiência de pessoas comuns e seu modo de se posicionarem como sujeitos ativos na comunidade em que vivem. Os moradores da Comunidade do Rosado/RN foram agentes de um processo histórico em que, no seu dia a dia, construíram e (re)construíram seus espaços com base nas relações sociais.
} 
Rev. Interd. em Cult. e Soc. (RICS), São Luís, v. 6, n. 1, p. 214- 234, jan./jun. 2020

ISSN eletrônico: 2447-6498

As narrativas desses sujeitos são ouvidas e $\operatorname{gravadas}^{8}$ no alpendre de Dona Morena $^{9}$, desde o primeiro encontro, das rodas de conversa, das visitas na residência de Dona Rosarinha, no bate-papo com Neneu nas Dunas do Rosado e no EcoPosto ${ }^{10}$ e nos III e IV Seminários de Narrativas (Auto)Biográficas realizados na Faculdade de Educação (FE/UERN). Nesses encontros, realizamos a construção, gravação e escrita das narrativas orais dos sujeitos da pesquisa, a partir de quatro sessões de narrativas com os participantes.

As entrevistas foram semiestruturadas e realizadas no formado de narrativas, que permitiram, com a leitura e interpretações, identificarmos se os saberes da experiência são compartilhados e contribuem para a formação no cotidiano na comunidade. Falamos da vida na comunidade; dos saberes da experiência dos mais velhos; do artesanato; da pesca e da agricultura, entre outras conversas, das quais boa parte estará escrita nesta pesquisa.

No descortinar desta viagem, no primeiro momento embarcamos nos saberes da experiência para a formação do cotidiano de homens e mulheres do lugar, por meio de suas lembranças e das memórias individuais e coletivas guardadas no tempo. E no segundo e último momento, navegamos nas narrativas dos saberes da experiência dos mais velhos: lições para os jovens do lugar. Trabalhar com narrativas de história de vida, significa abrir um leque de oportunidades para que os sujeitos comuns utilizem o poder da palavra para narrarem a si mesmos, a sua geração, o seu passado através da memória individual e coletiva.

\section{SABERES DA EXPERIÊNCIA PARA A FORMAÇÃO DO COTIDIANO DE HOMENS E MULHERES DO LUGAR}

Ensinar, aprender, conviver e ser atuam como quatro pilares inspirados no Relatório apresentado à UNESCO pela Comissão Internacional para a Educação do Século XXI (DELORS, 2001). Por sua vez, esses pilares darão sustentação para o entendimento da construção do cotidiano na comunidade. Esse cotidiano surge como espaço fértil para o estudo

\footnotetext{
${ }^{8}$ Para todos os sujeitos deste estudo perguntamos se aceitavam participar da pesquisa e se concordavam em assinar o Termo de Consentimento Livre e Esclarecido (TCLE) e o termo de autorização de uso de imagem das narrativas e da publicação. Consideramos o respeito pela dignidade humana e pela especial proteção devida aos participantes das pesquisas científicas envolvendo seres humanos e consideramos o desenvolvimento e o engajamento ético. Explicamos sobre a eticidade da pesquisa, sobre os aspectos pesquisa envolvendo seres humanos e ressaltamos o que deve atender aos fundamentos éticos, como consta na Resolução no 510/2016.

${ }^{9}$ Os nomes dos entrevistados citados neste trabalho são nomes fictícios, escolhidos pelos próprios moradores da comunidade, pois cada nome tem um significado e pertença pela convivência do lugar onde esses indivíduos moram.

${ }^{10}$ Criado em 2009 pelo IDEMA/RN na intenção de proteger e preservar as Dunas do Rosado, como também de barrar pessoas que apresentem atitudes suspeitas nas áreas próximas à Comunidade do Rosado/RN.
} 
Rev. Interd. em Cult. e Soc. (RICS), São Luís, v. 6, n. 1, p. 214- 234, jan./jun. 2020

ISSN eletrônico: 2447-6498

dos saberes da experiência e como lugar de produção de história, de pluralidade de ações e tensões que refletem uma política de sobrevivência. Nesse lugar, o cotidiano manifesta-se na relação entre homens e mulheres comuns, povos simples, cheios de anseios de permanecer no lugar, desejar, planejar e sonhar com dias melhores para a comunidade, que ora erram, ora acertam, nesse processo de construção e formação de suas subjetividades.

Para este estudo, o foco são os saberes da experiência de homens e mulheres, sujeitos com uma dinâmica social, que estão situados no tempo e no espaço, portanto, são históricos. Bondiá (2002) resume bem essa relação ao afirmar que o saber da experiência é um saber que não pode separar-se do indivíduo concreto em quem encarna. O significado de experiência, um dos conceitos basilares desta pesquisa, vem do latim experiri, isto é, provar, experimentar. A experiência é a ação de nos colocarmos para o outro e com o outro. É, em primeiro lugar, para Bondiá (2002), um encontro ou uma relação com algo que se experimenta que se prova. Segundo o autor, a experiência é o que passa e o que acontece aos sujeitos. Contudo, dentro da experiência existe um sujeito da experiência, o lugar da experiência e os acontecimentos da experiência. Esses pontos serão observados no decorrer desta viagem através das narrativas dos sujeitos da Comunidade do Rosado/RN.

No velejar pelas histórias de vida, serão conhecidos agora os saberes da experiência sobre a formação dos moradores da Comunidade do Rosado/RN. No local, as tradições e os costumes herdados dos antepassados ainda estão muito presentes nas formas de convívio, mesmo diante do advento das tecnologias. Isso demonstra que existe uma relação harmoniosa entre seus moradores.

O destino desta viagem é visibilizar as experiências de homens e mulheres, repassadas de geração a geração, a partir das narrativas de quatro moradores centrais, que vivenciaram e vivem experiências na comunidade. Iniciamos pelo narrador Neneu ${ }^{11}$, de 60 anos. Em sua fala, ele explicou que seu pai nunca foi pescador, sempre trabalhou na área da salina e agricultura. Contou que, desde os oito anos de idade, acompanhava seu pai. De sua memória, Neneu trouxe estas lembranças:

[...] Ele já me ensinou a trabalhar no roçado, pegando na enxada, pegando no facão, no machado, e a gente começou com 10 anos de idade fazendo essas atividades, e sempre foi assim. A partir dos meus 25 anos [...], pude dizer assim, eu não vou mais trabalhar na agricultura, vou deixar a agricultura, eu vou é pescar. Aí comecei a pescar eu não tinha nenhuma, assim, experiência com pesca, mas, eu fui começar a pescar com um caba novo ainda na pesca, mas que já vinha velho na atividade do avô dele, do pai dele. Ainda hoje mora no Rosado, é um colega meu, Nego velho.

\footnotetext{
${ }^{11}$ Não é o seu nome de batismo, mas como gosta de ser chamado na comunidade.
} 
Rev. Interd. em Cult. e Soc. (RICS), São Luís, v. 6, n. 1, p. 214- 234, jan./jun. 2020

ISSN eletrônico: 2447-6498

Comecei a pesca mais ele, tinha muita experiência. Novo, vista boa para conhecer os montes e ver tudo de perto [...] Ele me ensinou muita coisa, aprendi muita coisa com esse rapaz mais experiente do que eu na pesca, quer dizer, ele na pesca, e eu na pesca com experiência na agricultura. Tanto ele me ensinava na pesca, como eu dizia o que era o bom que tinha na agricultura, porque ele não tinha experiência na agricultura, né, mas, ele tinha muita experiência na pesca [...] (Narrativas ${ }^{12}$ de Neneu, morador da Comunidade do Rosado, em Porto do Mangue/RN, 20/07/2017).

Os saberes da experiência são colocados nas narrativas de Neneu como algo apaixonante. Ele expressa o prazer de aprender com seu pai. De acordo com suas narrativas, tais experiências foram ensinadas e repassadas de pai para filho e entre os próprios moradores, no dia a dia na comunidade, estabelecendo uma troca de saberes adquiridos pelos mais experientes ao logo da vida.

Sobre as experiências e os ensinamentos na agricultura, Neneu conta que seu pai, antes de ir para o trabalho na salina, deixava ordem em casa. Ele determinava tarefas para serem realizadas no roçado, como limpar o terreno, cuidar dos animais e não deixar que entrassem no roçado, para que não comessem as plantações. Neneu lembra que, no inverno, seu pai confeccionava enxadas pequenas para os filhos, ainda crianças. Desse modo, podiam trabalhar na limpeza dos matos e na plantação de milho e batata. Essa era a forma como aprendiam na/com a agricultura.

O relato do morador permite compreender que os saberes da experiência, como afirma Tardif (2012), resultam do próprio exercício da atividade profissional dos sujeitos. Esses saberes são produzidos por meio da vivência, seja individual ou coletiva, de situações específicas relacionadas ao espaço estabelecido com o outro. Através das experiências vivenciadas com o seu pai, Neneu conseguiu construir relações significativas para sua vida. Hoje, ele procura passar o que aprendeu para os mais novos da comunidade e fica feliz quando os jovens demonstram o interesse em aprender. O morador assim se pronunciou:

[...] A minha luta foi essa aqui. E hoje eu pesquei 20 e poucos anos. Nunca deixei de ser agricultor e nem de ser pescador, aí deixei a pesca em 2005. Hoje está com 12 anos que deixei de pescar. Deixei de pescar porque não sou mais um profissional da pesca. Fiquei só na agricultura mesmo. Hoje já estou aposentado. Graças a Deus, com 60 anos, me aposentei como agricultor, né, e estou ensinando agora os meus netos a trabalhar [...] (Narrativas de Neneu, morador da Comunidade do Rosado, em Porto do Mangue/RN, 20/07/2017).

\footnotetext{
${ }^{12}$ Todas as transcrições das entrevistas estão nos mesmos termos utilizados pelos participantes, tal como está escrito (ipsis litteris), respeitando a identidade e as linguagens locais dos povos da comunidade.
} 
Rev. Interd. em Cult. e Soc. (RICS), São Luís, v. 6, n. 1, p. 214- 234, jan./jun. 2020

A experiência narrada por Neneu permite perceber que, na Comunidade do Rosado/RN, existe uma relação entre os saberes da experiência, de saber-fazer e de saber-ser de forma individual e coletiva. Entre o tempo e o espaço, residem os sujeitos e os conhecimentos de aprendizagens dos saberes da experiência em coletividade. Nas marés da vida que os povos do mar do local educam. No compartilhar uns com os outros, constroem uma vida de possibilidades no mundo em que vivem.

Os saberes da experiência são resultantes dos conhecimentos e ensinamentos aprendidos ao logo da vida familiar e social, no decorrer da trajetória de vida, no próprio lugar de convívio na comunidade, por meio das relações estabelecidas entre si e com o outro. Conforme Martins (2000), pelo seu estranhamento em relação a si próprio.

Quando Neneu narra como é trabalhar na agricultura e a forma como aprendeu os ofícios de seu pai e outros da comunidade, relembra as experiências que construiu na convivência com o outro e enxerga que a forma de plantar e viver no/do campo sempre foi de um jeito simples. Ele explica:

\begin{abstract}
Para trabalhar na agricultura tem que ter experiência para plantar o milho, para limpar a terra, porque se toca na espiga o milho não cresce, fica atrofiado. Tem que limpar o milho, mas não pode bater na área no tronco dele, se bater, o milho não enche. Tudo isso são experiências do agricultor. As pessoas acham que isso não existe, mas, existe. Hoje, as pessoas têm um trator, cultivador. Ele limpa do jeito que ele quer com o trator. Depois que eles colocam o trator dentro também não vão mais limpar. Antes disso, tudo era manual, na enxada e no braço mesmo. Aí é isso que a gente aprendia, fazer um roçado, tinha que ensinar como se utiliza uma vara. A vara é para entrançar ou é para amarrar, a vara para amarrar é diferente da vara para entrançar na estaca, vamos dizer assim, porque você não tem como amarrar uma vara torta, e você não tem como fazer uma cerca com a vara lenheira, tem que ser torta. Tudo vem da experiência. Você pode até fazer uma cerca com a vara lenheira, mas poderá torar. Já a torta não, já vem no ponto. Fazer uma cerca para amarrar bem lenheira tem que tá no ponto, tudo isso são experiências que tem o agricultor (Narrativas de Neneu morador da Comunidade do Rosado, em Porto do Mangue/RN, 07/09/2017).
\end{abstract}

A experiência ocorre quando vivenciamos com o outro, quando nos alimentamos, com e pelo outro. Neneu, nesse sentido, é um exemplo do sujeito da experiência visto que está sempre pronto para ajudar o outro. Vivenciando no momento a aposentadoria, permanece sempre em pé, erguido, e apodera-se de si mesmo. Torna-se cada vez mais protagonista de sua própria história e permite construir com o outro o protagonismo também. Para Bosi (1994), quando os sujeitos relatam suas mais distantes lembranças, referem-se, em geral, a fatos que foram evocados, muitas vezes, pelas suas testemunhas. A autora afirma que somos de nossas 
Rev. Interd. em Cult. e Soc. (RICS), São Luís, v. 6, n. 1, p. 214- 234, jan./jun. 2020

ISSN eletrônico: 2447-6498

recordações apenas uma testemunha que, ocasionalmente, precisa do outro para confirmar o seu próprio olhar. Em complemento, Bosi (1994, p. 407) diz:

É preciso reconhecer que muitas de nossas lembranças, ou mesmo de nossas ideias, não são originais, foram inspiradas nas conversas com os outros. Com o correr do tempo, elas passam a ter uma história dentro da gente, acompanham nossa vida e são enriquecidas por experiências e embates.

Diante do exposto acima, questionamos: Quais as lembranças da infância dos moradores da Comunidade do Rosado/RN? Quais experiências os moradores da Comunidade do Rosado/RN aprendem com outro? Segundo Bosi (1994), a história dos sujeitos é dividida em períodos, os quais marcam todos os acontecimentos vividos no individual e no grupal, em diferente tempo na comunidade. Para a autora, cada geração tem, de seu lugar, a memória de acontecimentos, que permanecem como pontos de demarcação em sua vida. Esses acontecimentos são vividos em diferentes contextos, cada um relembra passagem pela memória individual e coletiva.

Destacamos as lembranças e lições de aprendizagem de uma narradora, Dona Morena $^{13}$, de 54 anos. Em suas narrativas, ela conta como aprendeu com os mais velhos, na época de criança. Além disso, afirma que esses ensinamentos ficaram como aprendizagem para toda vida. O que sabe até hoje, na comunidade, agradece aos seus avós e seus pais. A moradora ainda revela:

Aprendi a rezar a partir dos meus oito anos. A minha avó me ensinava a rezar todos de joelho, no pé do oratório, com as mãos postas. Rezar e agradecer pelo nosso pão de cada dia, pedir proteção para as nossas famílias. Esses saberes aprendi com minha avó. Eu achei tão bom que já repassei para os meus filhos, desde que eles aprenderam as palavras papai e mamãe. Eu primeiro comecei ensinando a rezar, comecei ensinando uma Ave Maria, nome do Pai, depois o Pai Nosso, assim sucessivamente. Aí, eu lembro quando eu era criança, sentava no chão com a minha mãe para remendar as roupas do meu pai, era necessidade mesmo naquela época, não era por beleza não [...]. Eu era tão pequena que ela alinhavava para eu costurar, para não fica torto e não sair do lugar do buraco. Eu achava tão bom, passava a tarde, era depois do almoço, fica aqui perto da porta. Costurava na mão mesmo, não tínhamos máquina de costura (Narrativas de Dona Morena moradora da Comunidade do Rosado, em Porto do Mangue/RN, 07/09/2017).

Nas narrativas de Dona Morena, percebemos o amor em ensinar e aprender. Seu desejo em aprender era prazeroso. As experiências da sua avó e de sua mãe alimentavam esse desejo de aprender com o outro. Quanto às lembranças da infância, fizeram Dona Morena voltar no tempo e perceber como sua infância foi construída por lições de aprendizagens.

\footnotetext{
${ }^{13}$ Esse nome foi dado quando ainda era menina, é uma forma carinhosa de ser chamada na comunidade.
} 
Rev. Interd. em Cult. e Soc. (RICS), São Luís, v. 6, n. 1, p. 214- 234, jan./jun. 2020

ISSN eletrônico: 2447-6498

Todos esses ensinamentos, ao longo de sua vida, alimentam sua memória até hoje. Ela nutre maior interesse de que eles sejam repassados para as novas gerações da comunidade, quais sejam: rezar, costurar e, também, cozinhar.

Os espaços da memória estão guardados nas lembranças da infância e da juventude, na verdade, estão presentes no nosso dia a dia, seja nas brincadeiras, fazeres do lar, conversas no terreiro. São lembranças aquecidas na memória de quem vive na comunidade. Segundo Pollak (1992), a memória é uma operação coletiva dos acontecimentos e das interpretações do passado; ela reforça sentimentos de pertencimento e fronteiras sociais entre coletividades de tamanhos diferentes. Falar da infância remete a reviver o passado e lembrar como essa vivência foi relevante para o crescimento e amadurecimento. Dona Morena expressa, nas suas narrativas, como construiu uma infância feliz. Segundo ela:

\begin{abstract}
Quando era de tarde, corríamos em cima daquela serra. Chamava falésias, mas, a gente chama mesmo é de serra ou grotas. Bota as cabritas no chiqueiro para gente tirar o leite, comíamos pirão de café, mexido no fogo, feito do caroço do café torrado. Pilava no pilão e depois fazia o escaldado de café para comer com peixe assado. A gente quanto era criança, na nossa comunidade, na maioria era assim mesmo, era uma casa aqui outra bem longe uma das outras, a gente vivia assim. E outra coisa também que a gradeço a Deus até hoje é a educação que meus pais me deram. A gente ser pobre, mas ser honesto, porque ser pobre e não ter honestidade, não ter palavra e ter o nome sujo, é melhor morrer, isso aí foi a educação que meus pais me deram, e foi do mesmo jeito que passei para os meus filhos. Espero que eles repassem para os filhos deles. O que eu aprendi de bom eu passo para eles e também para as pessoas da comunidade [...] (Narrativas de Dona Morena, moradora da Comunidade do Rosado, em Porto do Mangue/RN, 07/09/2017).
\end{abstract}

A infância na comunidade é lembrada através da memória; Dona Morena relembra momentos de diversão e de fazeres. Era um tempo difícil, os moradores sobreviviam da pesca e da agricultura, os alimentos eram extraídos da própria natureza. As comidas eram feitas de forma artesanal. Mesmo com dificuldades, os moradores, até hoje, preservam o respeito e os ensinamentos dos mais velhos do lugar, a educação prevalece entre seus membros, os bons modos são passados de pai para filho.

A memória do sujeito, conforme explica Bosi (1994), depende do seu relacionamento não só pessoal, mas familiar, grupal, social da memória. A importância das primeiras lições no convívio familiar é expressada na fala de Dona Morena, ao relembrar a infância de tempos que não voltam mais, mas que ficaram marcados na memória. Para Halbwachs (1999), as lembranças permanecem coletivas porque são lembradas pelos outros, mesmo que se trate de acontecimentos nos quais só os autores estiveram envolvidos e com objetos que só eles viram. Isso porque, em realidade, nunca ninguém está só. Na memória de 
Rev. Interd. em Cult. e Soc. (RICS), São Luís, v. 6, n. 1, p. 214- 234, jan./jun. 2020

ISSN eletrônico: 2447-6498

Dona Morena, ficaram marcados, em especial, os valores familiares. Foram as lições de ensinamentos dadas pelos seus pais sobre educação, honestidade e respeito que ela traz consigo e repassa para seus filhos. O maior desejo de Dona Morena é que esses valores permaneçam vivos na comunidade e que sejam transmitidos para os mais jovens.

Os encantos do lugar, as lembranças da infância, as dificuldades, a força e a paixão por pertencer a essa comunidade superam e resistem às adversidades do tempo vivido. No encontro com as narrativas dos povos do mar da Comunidade do Rosado/RN, os saberes da experiência de pescar, plantar, costurar, rezar e cantar dos mais velhos ensinam os jovens a arte de serem povos do mar. Colocam em suas mãos os saberes da experiência, a competência no que fazem. São esses saberes do dia a dia, do senso comum, que, para Martins (2000, p. 59), representam algo "comum não porque seja banal ou mero e exterior conhecimento. Mas porque é conhecimento compartilhado entre os sujeitos da relação". Isso implica dizer que sem significado compartilhado não há interação.

$\mathrm{Na}$ Comunidade do Rosado/RN, está presente a força pelo diálogo alimentado pelos fazeres comuns, que permeia a interação dos sujeitos do lugar. No local, são compartilhados significados em coletividade. Dona Rosarinha ${ }^{14}$, uma senhora de 79 anos, é uma professora aposentada que passou os saberes da experiência de costurar e fazer almofadas para Dona Morena, que repassa esses ensinamentos para outros sujeitos da comunidade. Para Martins (2000), são esses sujeitos comuns, na vida cotidiana, que, na prática, criam as condições de transformação do impossível em possível.

As histórias de vida e formação de Dona Rosarinha são constituídas de lembranças e experiências vividas ao longo da existência. Dentre essas lembranças, a moradora destaca o compromisso com o seu trabalho, regado de amor e paixão pela arte de ensinar e aprender. Suas narrativas são lições de vida, sem limitação para expor suas memórias. Pelo contrário, todas as narrativas voltam ao passado, que permanece vivo nas suas lembranças de hoje. A sua dedicação pela profissão de educar permanece viva, sendo perpassada pelo desejo de continuar na missão que escolheu, de ensinar o que aprendeu com os seus pais e parentes. Nas palavras de Dona Rosarinha:

O meu saber foi assim: minha mãe me ensinou a fazer crochê, minha tia fazia ponto de cruz, eu aprendi com elas [...] Depois, comecei a fazer o tricô, aprendi com minha madrinha. Fazia muito sapatinho para recém-nascido. Depois do sapatinho, foi bordado na máquina, eu fazia lençóis de cama, fazia, e o pessoal via e comprava, por

\footnotetext{
${ }^{14}$ Não é seu nome de batismo. Ela conta que "se chamaria Maria do Rosário, mas, seus pais batizaram com outro nome". Rosarinha é como gosta de ser chamada na comunidade.
} 
Rev. Interd. em Cult. e Soc. (RICS), São Luís, v. 6, n. 1, p. 214- 234, jan./jun. 2020

que eu precisava, né? Eu ainda sei bordar de máquina (Narrativas de Dona Rosarinha, moradora da Comunidade do Rosado, em Porto do Mangue/RN, 07/09/2017).

Os saberes da experiência, para Dona Rosarinha, são as experiências compartilhadas com o outro, por isso tem um cuidado e zelo pelo que faz. A arte de costurar, bordar, cantar e ensinar veio dos seus antepassados. Uma das atividades que ela preserva são as cantigas do passado, que cantava na escola e na igreja. No entanto, a vida não é feita apenas de bons momentos. Reside em sua memória um momento de muita tristeza e superação, quando perdeu seu marido. Passaram-se treze anos, mas a tristeza e a ausência dele não a fazem desistir de participar das atividades da comunidade. Ela continua fazendo as brincadeiras com as meninas no pastoril. Segundo ela: "é muito interessante, eu acho, e dou mil graças a Deus do que eu sou, do que eu faço com minhas amigas da minha comunidade. Trabalho na igreja e, assim, a gente continua".

No percurso pela memória desses sujeitos, as histórias de vida das narrativas (auto)biográficas representam muito mais que o ato de contar fatos, pois permitem registrar e captar os acontecimentos individuais ou coletivos dos sujeitos em formação, contribuindo para a ação-reflexiva desses sujeitos. Qualquer grupo tem sua história e essa história é construída e reconstruída por meio da convivência dos sujeitos em sociedade. Para Bosi (1994, p. 90), “[...] a história deve reproduzir-se de geração a geração, gerar muitas outras cujos fios se cruzem, prolongando o original, puxado por outros dedos". Por meio das narrativas dos sujeitos entrevistados, é percebida uma construção da formação, a partir da coletividade, adquirida pelos ensinamentos dos mais experientes da comunidade.

No balanço do mar do Rosado, os saberes da experiência são passados de um para o outro. Dona Rosarinha, em seu caderno, que usa para escrever os cantos, cola toda a sua história e compartilha os seus saberes com a comunidade. E Dona Morena, por meio dos seus ensinamentos como rezadeira e artesã, repassa os seus saberes de rezar e de preservar os valores da sua comunidade. Por sua vez, Neneu tem ensinado, como membro da associação, pescador e agricultor, seus saberes na coletividade apresentando o que aprendeu com o outro.

Cada um usa aquilo com que se identifica, no seu cotidiano, para repassar saberes e valores. Segundo Martins (2000, p. 102), “[...] o cotidiano não tem sentido divorciado do processo histórico que o reproduz". Dessa forma, as lembranças extraídas da memória dos mais velhos assumem fundamental importância para a Comunidade do Rosado/RN. São 
Rev. Interd. em Cult. e Soc. (RICS), São Luís, v. 6, n. 1, p. 214- 234, jan./jun. 2020

ISSN eletrônico: 2447-6498

lembranças cultivadas da vivência e das experiências das gerações passadas a serem revividas pelas gerações futuras.

Os relatos revelam experiências compartilhadas na comunidade. Dona Morena esclarece isso quando diz: "estou fazendo almofadas que aprendi com Rosarinha". Dona Rosarinha conta que ensinou Dona Morena e afirma: "passei o que eu sabia para ela, ela aprendeu tudo, é uma aprendizagem, ela ainda está aprendendo outras formas de trabalhar com as almofadas". Nessa experiência, o importante para Dona Rosarinha foi o interesse de Dona Morena em aprender.

Para Dona Rosarinha, isso representa a valorização dos seus ensinamentos. Nessa relação, existe uma parceria entre a professora e a aluna. Dona Rosarinha relata que Dona Morena começa a peça e ela faz os acabamentos. A arte de fazer almofadas é apenas uma das que Dona Rosarinha aprendeu e procura repassar para as mais jovens. As narrativas revelam que os saberes da experiência estão sendo repassados de um para o outro, na relação de troca de saberes.

\section{NARRATIVAS DOS SABERES DA EXPERIÊNCIA DOS MAIS VELHOS: LIÇÕES PARA OS JOVENS DO LUGAR}

Narrativas de histórias de vida e saberes da experiência dos mais velhos da Comunidade do Rosado/RN ganham destaque aqui como saberes, que ensinam a ser povos do mar e do campo. O sujeito da experiência, para Bondiá (2002), está inserido em espaços de lugares e dos acontecimentos. Se a experiência é o que acontece ao sujeito, e se o sujeito da experiência é um território de passagem, então, a experiência é uma paixão, porque o sujeito da experiência não é o sujeito da informação, não é o da opinião, não é um sem trabalho, sem ritmo, sem pensar no que faz no dia a dia; o sujeito da experiência é o que quer vivê-la com o outro. Ele sente a experiência com paixão. Na Comunidade do Rosado/RN, os moradores expressam a paixão pelo que fazem e pelo que sabem. Viver em comunidade é reconhecer o seu lugar de pertencimento e respeitar o outro.

Segundo Bondiá (2002), a palavra paixão pode referir-se a várias coisas. Ela é um elemento da experiência. Sem paixão não se vivencia o sujeito da experiência, porque os saberes da experiência se dão na relação entre o conhecimento e a vida humana, e eles não podem separar-se do indivíduo concreto em quem encarnam. Sem paixão não é possível 
Rev. Interd. em Cult. e Soc. (RICS), São Luís, v. 6, n. 1, p. 214- 234, jan./jun. 2020 ISSN eletrônico: 2447-6498

capturar a experiência, nem fazer referência ao outro. Não se pode pensar em si mesmo, no outro, sem essa paixão pelo outro.

O Rosado é uma comunidade que, mesmo com o surgimento das novas tecnologias, mantém as tradições deixadas pelos primeiros habitantes do lugar. Seus moradores, residentes na comunidade, manifestam os desejos da memória nos seus espaços comuns, como a vida no local, onde se preserva a natureza contra as modificações promovidas pelo homem, nas lutas diárias e nas práticas solidárias aos sentidos atribuídos às experiências vividas. Para Elias e Scotson (2000), a comunidade é um grupo organizado em cujo seio está contida a família, que em sua totalidade pode viver em algum tipo de área local. A esses espaços dá-se o nome de comunidades, no sentido de formarem grupos sociais coesos, em uma rede de relações sociais. São espaços de diferentes saberes, por meio dos quais os sujeitos, na convivência com o outro, confirmam-se, modificam-se e ampliam suas memórias, bem como reconstroem o passado e planejam o futuro.

Nas narrativas de moradores percebemos experiência individual e coletiva sob a forma de habitus e de habilidades, de saber-fazer e de saber-ser (TARDIF, 2012). Apontamos a memória como referência central, que traz a trajetória desses saberes das experiências dos moradores da comunidade nas lembranças e experiência de vida. Para enfatizar os saberes da experiência na comunidade, foram lançadas duas questões: os mais velhos estão passando seus saberes para os mais jovens? E os mais jovens estão tendo o interesse em aprender? É necessário destacar que, na comunidade, os moradores praticam duas importantes atividades: agricultura e a pesca.

Dona Morena relata que os jovens vão para a vazante, limpam a terra para plantar e conhecer como lidar com essa atividade, mostrando que eles aprendem com os mais experientes da comunidade. Segundo as narrativas de Dona Morena, os jovens da comunidade têm o interesse de aprender com os mais velhos, sendo estabelecida a relação do ensinar e do aprender. A moradora explica: "esse ensinamento ainda tem na nossa comunidade e espero que continue por muito tempo, para não deixar morrer a nossa cultura”.

Dona Rosarinha expressa como adquiriu suas experiências: "aprendi a costurar com minha mãe, ela me ensinou a ler e a escrever". Através dos saberes da experiência, aprendeu com sua mãe e tias. Aprendeu na relação com o outro: costura, crochê, tricô, bordado, almofadas, ensinar, entre outros. No momento atual, Dona Rosarinha passa seus saberes da experiência para os adultos e os jovens da comunidade, para a construção da formação. Seus saberes da experiência contribuíram para o seu crescimento, tanto profissional 
Rev. Interd. em Cult. e Soc. (RICS), São Luís, v. 6, n. 1, p. 214- 234, jan./jun. 2020

quanto pessoal. Desenvolveu, com sua arte de educar, a busca da formação para muitos moradores da comunidade.

Entrelaçamos o estudo na voz de um jovem da Comunidade do Rosado/RN. Seus relatos estão relacionados às lições de aprendizagens e ao aprender com o outro. Ao longo de suas narrativas, é possível acessar a história da comunidade e conhecer sobre a origem e os acontecimentos de luta e resistência no lugar. Dos seus relatos, renascem os saberes advindos das experiências dos mais velhos da comunidade, repassados de geração em geração.

Chamamos o jovem de Escultor ${ }^{15}$. Conta que o seu maior objetivo é seguir em frente na profissão de artesão. Está com 32 anos de idade e trabalha como servidor público municipal, na própria comunidade. Nas horas vagas, no trabalho ou em casa, ele tira tempo para esculpir suas peças de madeira. O jovem, expressa o seu desejo de ser um artista profissional reconhecido e de ensinar o que aprendeu com seu pai para os jovens da comunidade. Afirma que fica encantado quando alguém aprende com suas lições, da mesma forma como aprendeu com seu pai. Como se pode notar, os sujeitos históricos organizam-se a partir das suas relações sociais e culturais e de um desejo comum, fortalecem-se em comunidade para alcançar os seus objetivos de forma coletiva.

Escultor é um exemplo de como os jovens da comunidade têm grandes oportunidades de aprender com os mais velhos, seja o manejo da pesca, o cuidar da terra, a agricultura ou as habilidades do artesanato. Essas atividades - praticadas na comunidade como meio de adquirir renda para ajudar nas despesas das famílias - podem ser exploradas pelos jovens por meio dos saberes da experiência dos mais velhos do Rosado.

Hoje, os jovens da comunidade estão divididos entre as atividades locais e os estudos, pois entendem que seguir os passos dos mais velhos é respeitar e valorizar os costumes e as tradições. A experiência relatada por Escultor demonstra que os saberes dos mais antigos da comunidade estão sendo passados às gerações posteriores e contribuindo para sua formação. Ele enfatiza: "Cresci um pouquinho e tenho muito para aprender e levar a minha profissão adiante, como pescador. Eu aprendi, não só com o meu pai, mas com os pescadores experientes da comunidade". O jovem Escultor relembra como construiu a profissão de pescador desde o início, sendo instruído dia a dia, na convivência com o outro na comunidade. Ele explica:

\footnotetext{
${ }^{15} \mathrm{O}$ nome fictício do jovem entrevistado é Escultor, por sua escolha. Explicou que gosta desse nome porque se identifica muito com a arte, assim, demostra sua identidade e pertencimento do lugar.
} 
Rev. Interd. em Cult. e Soc. (RICS), São Luís, v. 6, n. 1, p. 214- 234, jan./jun. 2020

ISSN eletrônico: 2447-6498

Eu aprendi na pescaria. Foi através de seu Cicero Cosmo, um senhor daqui do Rosado que, hoje, tem uns setenta e poucos anos, aposentado. Ele pescava, na época, bem perto da costa, e eu queria aprender a pescar de qualquer forma. Aí eu fugia de casa, sem que minha mãe visse. Eu tinha, na época, 10 anos. Minha mãe não deixava eu ir, mais eu fugia. Até que fui aprendendo [...]. Fui pegando amizade com os filhos dele e a gente foi crescendo um pouquinho e passando a pescar junto, eu e o Artur Cosmo, que, hoje, ainda continua pescando. E eu, aqui e acolá, ainda vou. Fomos pescando e, com o passar do tempo, fomos arriscando a mergulhar, a pescar mais distante. E eu passei a me arriscar a mergulhar, e fui aprendendo. E hoje mergulho, pego peixe, lagosta, tudo mergulhando [...] (Narrativas do jovem Escultor, morador da Comunidade do Rosado, em Porto do Mangue/RN, 24/08/2017).

Nas narrativas, percebe-se que os saberes da experiência são compartilhados pelos moradores mais velhos com os jovens desejosos de aprender. Nessa troca de saberes da experiência com o outro, é construída a formação. Segundo Josso (2010a), a formação distingue-se de duas formas: como um processo de mudança; e como projeto, produção de vida e de sentido. Ambos são importantes para que os jovens da comunidade, ao longo da aprendizagem, desenvolvam e desempenhem um papel decisivo em sua formação. Os jovens devem encarar os desafios e estabelecer metas para os futuros projetos que terão pela frente. $\mathrm{Na}$ comunidade, os jovens aprendem com os saberes da experiência com o outro, mas aprendem também com a paixão pelo conhecimento, com a pesca, a agricultura e o artesanato. Aprendem com a família, pelas tradições passadas de pais para filhos, mesmo que, no futuro, eles não queiram seguir os fazeres da comunidade.

O exemplo do jovem Escultor permite perceber que o aprendizado dos saberes na comunidade tem uma continuidade, graças ao costume e tradição de compartilhar as experiências dos mais velhos aos mais jovens. Escultor expressa uma paixão pelo que faz e é com esse sentimento que se constrói a experiência. O jovem explica que "os valores que a gente aprende não é só da gente, é pra gente passar adiante, porque, se você achou bom que alguém lhe ensinou, ensine para alguém, porque uma coisa só fica boa quando a gente divide com os outros". Essa reflexão do jovem mostra a construção de uma formação a partir do que aprendeu com os mais velhos.

Nas narrativas, nota-se que os saberes da experiência dos moradores da Comunidade do Rosado/RN são transmitidos e ensinados para os jovens, estabelecendo uma relação de aprender com o outro no lugar do outro. De acordo com Freire (1987), os sujeitos aprendem porque são seres sociais, porque a coletividade se faz no diálogo com outro e com o próprio mundo. Para os jovens, a pesca na comunidade caracteriza-se como uma forma de sobrevivência e também como um meio para adquirir aquilo que os pais não puderam dar. Dona Morena confirma esses fatos ao relatar: "tem alguns jovens que não querem fazer essas 
Rev. Interd. em Cult. e Soc. (RICS), São Luís, v. 6, n. 1, p. 214- 234, jan./jun. 2020 ISSN eletrônico: 2447-6498

atividades, querem apenas estudar". Identificamos, por meio das narrativas do jovem da Comunidade do Rosado/RN, que as lições de aprendizagem dos mais velhos, por meio dos saberes da experiência, estão sendo repassados para os mais jovens. Esses saberes da experiência, tais como pescar, plantar, esculpir, rezar e costurar, permanecem na comunidade, de modo que os próprios jovens aprendam e compartilhem uns com os outros em coletividade.

Ao narrarem as suas experiências, os moradores da Comunidade do Rosado/RN apropriam-se da sua própria história de vida e formam a si mesmos e com o outro. Na coletividade, constituem-se pelo sentimento de pertencimento do lugar; agem a partir de si e sobre o meio em que estão inseridos; lutam para manter viva a história; e idealizam projetos de sustentabilidade cultural e ambiental para a comunidade.

A trajetória de vida e as experiências dos moradores que são atores e autores desta pesquisa, por meio das memórias individuais e coletivas de Dona Rosarinha, Neneu, Dona Morena e o jovem Escultor, trazem vivências que marcaram lembranças dos lugares e dos acontecimentos e que estão guardadas na memória. Cada trajetória tem relação com a vida diária de cada um dos moradores na comunidade, com a família e com os amigos.

As narrativas dos quatro moradores centrais da Comunidade do Rosado/RN têm sua força no momento em que permitem aos sujeitos uma (re)significação da prática, na convivência diária, consigo mesmo e com o outro. É no cotidiano que se possibilita perceber como esses sujeitos constroem, experimentam e vivenciam as relações sociais no seu lugar de pertença. Esse exercício fortalece e remete a uma perspectiva positiva e retificadora do pensamento crítico e reflexivo do ser em formação. Para Delory-Momberger (2008, p. 99), “[...] a capacidade de mudança postulada nos procedimentos de formação pelas "histórias de vida" repousa sobre o reconhecimento da vida como experiência formadora e da formação como estrutura da experiência".

As narrativas das histórias de vida, para Josso (2010), constituem processos de formação, nos quais é possível situar histórias particulares em contextos coletivos. É nessa coletividade que os moradores da Comunidade do Rosado/RN constituem um procedimento de formação, na medida em que se instaura uma relação dialética entre o passado e o futuro e abre-se para os sujeitos um espaço de formação. Com base nos relatos deste estudo, é possível dizer que as narrativas dos quatro moradores centrais entrevistados da comunidade revelam o viver, o sonhar e o praticar o seu lugar de pertença. Os saberes da experiência são repassados pelos moradores, compartilhados uns com os outros no lugar, dessa forma, estão contribuindo 
Rev. Interd. em Cult. e Soc. (RICS), São Luís, v. 6, n. 1, p. 214- 234, jan./jun. 2020

ISSN eletrônico: 2447-6498

para a formação do cotidiano. Os sujeitos da comunidade relembram, por meio da memória, o início da formação da comunidade, as dificuldades de permanecerem no lugar, os ensinamentos das tradições, os saberes da experiência compartilhada com o outro em coletividade.

\section{CONSIDERAÇÕES FINAIS}

O Método (Auto)Biográfico, por meio das narrativas das histórias de vida, estabeleceu alternativa para a mediação entre as ações e a estrutura, ou seja, entre a história individual e a história social dos moradores da Comunidade do Rosado/RN. Por essa razão, requereu dos sujeitos o resgate de suas memórias.

Nesta pesquisa, viajamos nas memórias de homens e mulheres da Comunidade do Rosado/RN. Durante esse trajeto, compreendemos os saberes da experiência das mulheres da comunidade. Embarcamos nas lições das histórias de vida e de experiências desses moradores, com saberes passados de geração a geração, para serem compartilhados pelos jovens dessa comunidade. Navegamos pelas lembranças dos mais velhos, lembranças guardadas no tempo e repassadas na convivência entre homens e mulheres do lugar. Entre o tempo e o espaço, os homens e mulheres da Comunidade do Rosado/RN resistem com os conhecimentos de aprendizagens dos saberes da experiência. É no educar, no aprender e na comunhão com o outro que encontram a construção de uma vida de possibilidade no mundo em que existem.

As narrativas (auto)biográficas foram vistas como pontos de acesso às histórias de vida e saberes da experiência dos sujeitos comuns da Comunidade do Rosado/RN. A pesquisa nessa comunidade está além do espaço geográfico. Refletimos sobre outros elementos como: trabalho, luta, resistência, relações sociais e culturais, modo de vida, sonhos e anseios dos habitantes. As narrativas dos quatro moradores centrais entrevistados, Neneu, Dona Morena, Dona Rosarinha e Jovem Escultor, foram permeadas por troca de saberes, valoração do outro, respeito e desejo pela manutenção da identidade. Na comunidade, preserva-se o respeito dos jovens para com os mais velhos, os ensinamentos são passados de pai para filho. Os costumes, valores e tradições são mantidos no lugar.

Os relatos dos quatro moradores centrais da pesquisa foram um passaporte para uma viagem no tempo, passando por lugares e acontecimentos que marcaram a memória em comunidade. Suas histórias de vida e experiência foram ouvidas e gravadas, a fim de que não 
Rev. Interd. em Cult. e Soc. (RICS), São Luís, v. 6, n. 1, p. 214- 234, jan./jun. 2020

ISSN eletrônico: 2447-6498

se percam com o passar dos anos. Os moradores narraram suas histórias de vida e saberes da experiência na comunidade e expressaram um sentimento de pertencimento ao lugar. Os saberes da experiência, tais como pescar, plantar, ensinar, cantar, bordar, rezar, costurar, entre outros, estão sendo repassados pelos moradores, sendo compartilhados uns com os outros no lugar, dessa forma, estão contribuindo para a formação do cotidiano e vão sendo construídos pelos moradores ao longo da convivência em coletividade.

Para a realização desta pesquisa, o Método (Auto)Biográfico constituiu-se numa fonte riquíssima. Em um trabalho com essas características, as entrevistas narrativas com esses moradores da Comunidade do Rosado/RN assumiram grande contribuição. As narrativas são o elemento que impulsiona, irriga e dá vida a esta investigação. Muitas questões colocam-se para quem lida com as narrativas (auto)biográficas. É relevante ter atenção com a relação dialógica que se estabelece entre pesquisador e entrevistado e, sobretudo, com a dimensão social e dinâmica da memória.

\section{REFERÊNCIAS}

ALVES, Andreia Duarte. Histórias de pescadores: memórias de vidas submersas. Dissertação. Mestrado em psicologia. 2007. 180 f. Dissertação (Mestrado em psicologia) Universidade Estadual Paulista Júlio de Mesquita Filho. Assis. 2007.

BOGDAN, Robert e BIKLEN, Sari. Investigação qualitativa em educação: uma introdução à teoria e aos métodos. Portugal: Porto Editora, 1994.

BONDIÁ, Jorge Larrosa. Notas sobre a experiência e o saber de experiência. Revista Brasileira de Educação. No 19. Jan/Fev/Mar/Abr, 2002, p. 20-28. Universidade Estadual de Campinas, Departamento de Lingüística. Disponível em: www.scielo.br/. Acesso em: 31 mai. 2017.

BOSI, Ecléa. Memória e Sociedade. Lembranças de velhos. $3^{\text {a }}$ ed. - São Paulo: Companhia das Letras, 1994.

CARDOSO, Roseli da Silva. Os saberes da gente do mar: o imaginário e as experiências de vida dos pescadores da Vila do Treme, Bragança (PA). 2015. 185 f. Dissertação (Mestrado em Linguagens e Saberes na Amazônia) - Universidade Federal do Pará. Bragança. 2015.

DELORS, Jaques (Org.). Educação: um tesouro a descobrir. Relatório para a Unesco da Comissão Internacional sobre Educação para o Século XXI. Tradução José Carlos Eufrázio. 5. ed. São Paulo: Cortez; Brasília: MEC/ UNESCO, 2001.

DELORY-MOMBERGER, Chistine. Biografia e Educação: figuras do indivíduo-projeto. Natal - RN: EDUFRN; São Paulo: Paulus, 2008. 
Rev. Interd. em Cult. e Soc. (RICS), São Luís, v. 6, n. 1, p. 214- 234, jan./jun. 2020

ISSN eletrônico: 2447-6498

ELIAS, Norbert; SCOTSON, John L. Os estabelecidos e os Outsiders: sociologia das relações de poder a partir de uma comunidade. Rio de Janeiro: Jorge Zahar Ed., 2000. Disponível em: https://producoeseconhecimentos.files.wordpress.com/. Acesso em: 09 set. 2016.

FONSECA, Ana Cláudia Mafra da. Histórias de Pescador: as culturas populares nas redes das narrativas (Papary - Nísia Floresta - RN). 2005. 335 f. Tese (Doutorado em Letras) Faculdade de Letras, Universidade Federal da Paraíba. João Pessoa. 2005.

FREIRE, Paulo. Pedagogia do oprimido. 19ª . ed. Rio de Janeiro: Paz e Terra, 1987. Disponível em: www.dhnet.org.br. Acesso em: 27 dez. 2015.

HALBWACHS, Maurice. A memória coletiva. Presses Universitaires de France, 1990. Disponível em: lelivros.website/book/. Acesso em: 15 set. 2015.

JOSSO, Marie-Christine. Experiência de vida e formação. 2 ed. rev. e amp. Natal, RN: EDUFRN, São Paulo: Paulus, 2010.

JOSSO, Marie-Christine. Caminhar para si. Porto Alegre: EDIPUCRS, 2010a. Tradução de Albino Pozzer.

LIMA, Mariene Francine. Mares e Pescadores: narrativas e conversas em Itapoá. 2011. 109 f. Dissertação (Mestrado em Educação) - Universidade Federal do Paraná. Curitiba. 2011.

MARTINS, José de Souza. A sociabilidade do homem simples: cotidiano e história na modernidade anômala. 2. Ed. São Paulo: Hucitec, 2000.

PINEAU, Gaston. LE GRAND, Jean-Louis As histórias de vida; Tradução de Carlos Eduardo Galvão Braga e Maria da Conceição Passeggi - Natal: EDUFRN, 2012.

POLLAK, Michael. Memória e identidade social. Estudos Históricos, Rio de Janeiro, vol. 5, n. 10, 1992, p. 200-212. Disponível em: www.slideshare.net. Acesso em: 15 set. 2015.

SOUSA, José Josberto Montenegro. Culturas tradicionais no Ceará: nas dobras de narrativas em contendas sertanejas. 2009. 192 f. Tese (Doutorado em História Social) Pontifícia Universidade Católica de São Paulo. São Paulo. 2009.

SOUZA, Elizeu Clementino de. A Arte de Contar e Trocar Experiências: reflexões teóricometodológicas sobre história de vida em formação. Disponível em: EC Souza - Revista Educação em Questão, 2006. Acesso em: 15 set. 2015.

TARDIF, Maurice. Saberes docentes e formação profissional. Rio de Janeiro: Vozes, 2012. 